\title{
Does written informed consent adequately inform surgical patients? A cross sectional study
}

Erminia Agozzino* ${ }^{*}$, Sharon Borrelli, Mariagrazia Cancellieri, Fabiola Michela Carfora, Teresa Di Lorenzo and Francesco Attena

\begin{abstract}
Background: Informed consent (IC) is an essential step in helping patients be aware of consequences of their treatment decisions. With surgery, it is vitally important for patients to understand the risks and benefits of the procedure and decide accordingly. We explored whether a written IC form was provided to patients; whether they read and signed it; whether they communicated orally with the physician; whether these communications influenced patient decisions.
\end{abstract}

Methods: Adult postsurgical patients in nine general hospitals of Italy's Campania Region were interviewed via a structured questionnaire between the second and seventh day after the surgery at the end of the first surgical follow up visit. Physicians who were independent from the surgical team administered the questionnaire.

Results: The written IC form was given to $84.5 \%$ of those interviewed. All recipients of the form signed it, either personally or through a delegate; however, $13.9 \%$ did not know/remember having done so; $51.8 \%$ said that they read it thoroughly. Of those who reported to have read it, $90.9 \%$ judged it to be clear. Of those receiving the written consent form, $52.0 \%$ had gotten it the day before the surgery at the earliest $41.1 \%$ received it some hours or immediately before the procedure. The written IC form was explained to $65.6 \%$ of the patients, and $93.9 \%$ of them received further oral information that deemed understandable. Most attention was given to the diagnosis and the type of surgical procedure, which was communicated respectively to 92.8 and $88.2 \%$ of the patients. Almost one in two patients believed that the information provided some emotional relief, while $23.2 \%$ experienced increased anxiety. Younger patients (age $\leq 60$ ) and patients with higher levels of education were more likely to read the written IC form.

Conclusions: The written IC form is not sufficient in assuring patients and making them fully aware of choices they made for their health; pre-operative information that was delivered orally better served the patients' needs. To improve the quality of communication we suggest enhancing physicians' communication skills and for them to use structured conversation to ensure that individuals are completely informed before undergoing their procedures.

Keywords: Informed consent, Medical ethics, Surgery, Hospital, Italy

\footnotetext{
* Correspondence: erminia.agozzino@unicampania.it

Department of Experimental Medicine, Campania University L. Vanvitelli,

Section of Hygiene Via L. Armanni 5, 80138 Naples, Italy
}

(c) The Author(s). 2019 Open Access This article is distributed under the terms of the Creative Commons Attribution 4.0 International License (http://creativecommons.org/licenses/by/4.0/), which permits unrestricted use, distribution, and reproduction in any medium, provided you give appropriate credit to the original author(s) and the source, provide a link to the Creative Commons license, and indicate if changes were made. The Creative Commons Public Domain Dedication waiver (http://creativecommons.org/publicdomain/zero/1.0/) applies to the data made available in this article, unless otherwise stated. 


\section{Background}

Informed consent (IC) is a process by which a physician interacts with a patient, enabling the latter to make a knowledgeable decision regarding the treatment of his or her disease. IC consists not only of the form that patients must read and sign, it also involves oral communication that helps physicians establish a stronger relationship with the patients, which is considered by some to be a prerequisite for well-reasoned decision-making [1]. Moreover, two distinct but interrelated components characterize IC: the information about risks, benefits and alternatives and consent to undergo the proposed surgical procedure.

Italian jurisprudence has further broadened the meaning of IC to include information on supplies and equipment-as well as their service records-so that patients can opt to transfer to better-equipped facilities [2]. Despite these guidelines, implementing comprehensive IC is elusive.

Seeking informed consent is often a formal act in which a patient's signature is obtained, with physicians believing that an important obligation has been fulfilled regardless of whether the patient has been provided with adequate information about the medical intervention that is about to take place [3].

Challenges and limitations of IC are widely discussed in different health care settings for different patients typologies [4-9]. The four principles of biomedical ethics (autonomy, beneficence, nonmaleficence and justice) are generally taken into account in these discussions [10]. Among them, the more pertinent to the ethics of IC is the principle of autonomy for which the person has the right, at all ages and stages of life, to have for himself, to the extent permitted by ethical evidence and by law, choosing whether to accept or refuse the ad, also offered from outside, on its health. And that it Is possible only as consequences of an adequate information.

We must remain mindful that there are patients who will not to be informed, who will not participate in treatment decisions and who will experience anxiety or other negative effects (this is known as "nocebo effect"), especially if they become aware of serious side effects due to surgery [11-14].

Surgical IC is particularly critical for the following reasons: the acute and the particularly vulnerable condition of patients; the urgency of the processes that must take place; the high technological level; the multiplicity of critical points of the process that can cause serious harm to the patient. Consequently, a greater difficulty arises for the patient to understand all these aspects and to decide accordingly, which includes consideration of any alternatives to the surgery $[15,16]$.

We explored whether the written IC form was delivered to patients, whether they signed the consent form and whether they read and understood the information about the surgical intervention. We also investigated verbal communication between patients and physicians and whether it affected patient decision making.

\section{Methods \\ Setting}

An epidemiological cross-sectional study was conducted between January 2016 to June 2016 to assess the quality of the IC process at nine general hospitals within Italy's Campania Region. We selected these facilities to ensure representative coverage of the entire region territory as well as the representative participation of different general-hospital typologies. Four of the facilities are known as specialized hospitals (aziende ospedaliere), two are local hospitals (presidi ospedalieri), one is a teaching hospital (azienda ospedaliera universitaria), and two are private hospitals.

\section{Participants and Data Collection}

Post surgery adult patients admitted in general surgery and giving the written consent to participate were included in the study. All patients were recruited in general surgery departments and interviewed via a structured questionnaire between the second and the seventh day after surgery, at the end of their first surgical follow up visit. Children under 18 years of age and patients who required intensive care or were taken back into surgery were excluded. Subjects were interviewed by one of four physicians adequately trained. All of them are specialized in Public Health. Epidemiology and Hospital Organization, and were independent from the surgical team and from the hospital. All the patients were interviewed in a room where their privacy could be ensured, and their answers remained confidential.

\section{Questionnaire}

The questionnaire, which was divided into four sections, was formulated after an extensive literature search. The four questionnaire sections were as follows:

- Section 1: Descriptive characteristics of the study participants ( $n=6$ questions)

- Section 2: Information on the delivery, signing, reading and comprehensibility of the written IC form ( $n=6$ questions)

- Section 3: Additional information (acquired orally) on the explanation of the consent and on the effect of the written and oral information ( $n=11$ questions)

- Section 4: Information on the surgery outcome and on the post-surgical period ( $n=4$ questions)

\section{Sample Size}

The sample size was estimated to be at least 400 subjects, assuming a $50 \%$ of expected prevalence of the 
most important variables (delivery, reading and understanding the IC form), with precision of $5 \%$ and level of significance of $95 \%$.

\section{Data analysis}

Descriptive statistics were computed using SPSS 21. The prevalence of delivery, reading and understanding of IC were calculated. Then, several bivariate analysis were performed to determine whether socio-demographics characteristics are in relationship with delivery, reading and understanding IC. Furthermore, we checked whether patients to whom the IC form had been explained or who had received additional oral information were more satisfied. Stratification analysis was used when crude Odds Ratio (OR) were statistically significant in bivariate analysis.

\section{Results}

Among the 632 patients enrolled from the various hospitals, $72(11.4 \%)$ did not adhere to the survey. Among the remaining 560 participants, $65.2 \%$ were female and $96.2 \%$ were Italian. Just over a third (65.5\%) were under 60 years of age, $68.8 \%$ were married and only $12.0 \%$ had graduated; $85,4 \%$ of patients underwent a surgical procedure of medium or high complexity (Table 1 ).

Most respondents $(84.5 \%)$ personally received a written IC form or they reported that they delegated to a parent or a relative, $1.6 \%$ declared that they did not get it, and the others (13.9\%) did not recall receiving it. Among those patients who did receive the IC form, all signed it personally or through a relative or parent, but only $51.8 \%$ reported having read it thoroughly. Among those who read the IC, $90.9 \%$ judged it to be clear and 9.1\% deemed it partially understandable. No one considered it incomprehensible. Approximately half of patients received the written IC form a day before surgery (at the earliest), while $41.1 \%$ received it within some hours or immediately before surgery. Forty-five percent of patients receiving the written forms were given them by the surgeon who performed the procedure (Table 2).

Not all patients had the written consent for explained to them; it was explained orally only to $65.6 \%$; however, $93.9 \%$ of patients received further oral information; among these $68.6 \%$ judged this information to be incomplete, and only $31.4 \%$ considered it complete.

The information was provided progressively during pre-operative examinations (66.7\%) and, according to most $(97.1 \%)$ recipients were understandable, as shown in Table 3.

Most attention was given to the diagnosis (Table 4), communicated to $92.8 \%$ of patients, and to the type of surgical procedure (88.2\%); less attention was given to the prognosis $(74.2 \%)$, post-operative progress $(68.6 \%)$, benefits of the surgery (68.0\%), consequences of a
Table 1 Socio-demographics characteristics of patients $(n=560)$

\begin{tabular}{|c|c|c|}
\hline & $\mathrm{n}$ & $\%$ \\
\hline \multicolumn{3}{|l|}{ Sex } \\
\hline Female & 365 & 65.2 \\
\hline Male & 195 & 34.8 \\
\hline Total & 560 & 100.0 \\
\hline \multicolumn{3}{|l|}{ Age } \\
\hline $18-40$ & 206 & 36.8 \\
\hline $41-60$ & 161 & 28.7 \\
\hline $61-80$ & 163 & 29.1 \\
\hline$>80$ & 30 & 5.4 \\
\hline Total & 560 & 100.0 \\
\hline \multicolumn{3}{|l|}{ Marital Status } \\
\hline Married & 385 & 68.8 \\
\hline Unmarried & 104 & 18.6 \\
\hline Widow Nidower & 54 & 9.6 \\
\hline Separate/Divorced & 17 & 3.0 \\
\hline Total & 560 & 100.0 \\
\hline \multicolumn{3}{|l|}{ Education } \\
\hline Illiterate & 5 & 0.9 \\
\hline Primary School & 114 & 20.3 \\
\hline Middle School & 188 & 33.6 \\
\hline High School & 186 & 33.2 \\
\hline Degree & 67 & 12.0 \\
\hline Total & 560 & 100.0 \\
\hline \multicolumn{3}{|l|}{ Nationality } \\
\hline Italian & 539 & 96.2 \\
\hline Foreign & 21 & 3.8 \\
\hline Total & 560 & 100.0 \\
\hline \multicolumn{3}{|l|}{ Surgical Complexity } \\
\hline Low & 82 & 14.6 \\
\hline Middle & 275 & 49.1 \\
\hline High & 203 & 36.3 \\
\hline Total & 560 & 100.0 \\
\hline
\end{tabular}

missed treatment $(64.6 \%)$, existence of alternative therapeutic programs $(63.2 \%)$, chances of success $(61.8 \%)$, and possible surgical complications (53.6\%).

Among patients who received both written consent and oral information, only $19.6 \%$ were "a lot" or "somewhat" influenced to undergo to the surgery, whereas $69.6 \%$ would have consented to the surgery with or without the additional information (Table 5).

Among those who claim to have been influenced, $66.7 \%$ declared that they were mainly persuaded by the oral information, and $2.2 \%$ opined that they were more influenced by the written IC form. Among patients who received information, $88.2 \%$ were satisfied and did not 
Table 2 Modalities of acquisition of written IC $(n=560)$

\begin{tabular}{|c|c|c|}
\hline & $\mathrm{n}$ & $\%$ \\
\hline \multicolumn{3}{|l|}{ Have you received a written IC form? } \\
\hline Yes & 473 & 84.5 \\
\hline I don't know / I don't remember & 78 & 13.9 \\
\hline No & 9 & 1.6 \\
\hline Total & 560 & 100.0 \\
\hline \multicolumn{3}{|l|}{ Who signed it? ${ }^{a}$} \\
\hline Patient & 448 & 94.7 \\
\hline Patient + relative & 18 & 3.8 \\
\hline Relative & 5 & 1.1 \\
\hline Parent & 2 & 0.4 \\
\hline Total & 473 & 100.0 \\
\hline \multicolumn{3}{|l|}{ Did you read it? ${ }^{\mathrm{a}}$} \\
\hline Yes & 245 & 51.8 \\
\hline No, I did not want & 167 & 35.3 \\
\hline No, due to lack of time & 31 & 6.6 \\
\hline Partially / Distractedly & 30 & 6.3 \\
\hline Total & 473 & 100.0 \\
\hline \multicolumn{3}{|l|}{ Was it understandable? ${ }^{\mathrm{b}}$} \\
\hline Yes & 249 & 90.9 \\
\hline Partially & 25 & 9.1 \\
\hline No & 0 & 0.0 \\
\hline Total & 274 & 100.0 \\
\hline \multicolumn{3}{|l|}{ Time before the surgery ${ }^{a}$} \\
\hline Immediately before & 81 & 17.1 \\
\hline Some hours before & 113 & 24.0 \\
\hline The day before & 163 & 34.5 \\
\hline$>1$ day & 83 & 17.5 \\
\hline They can't remember & 33 & 6.9 \\
\hline Total & 473 & 100.0 \\
\hline \multicolumn{3}{|l|}{ Who delivered it? ${ }^{a}$} \\
\hline Operative surgeon & 212 & 44.8 \\
\hline Other surgeon & 160 & 33.8 \\
\hline Nurse & 34 & 7.2 \\
\hline Anesthetist & 13 & 2.8 \\
\hline Administration & 2 & 0.4 \\
\hline I don't remember & 52 & 11.0 \\
\hline Total & 473 & 100.0 \\
\hline
\end{tabular}

${ }_{\text {ancluding only those who received it }}$

$\mathrm{b}_{\text {including only those who received and read it }}$

believe they were in need of further details and, in fact, $64.4 \%$ of them reported that they had the opportunity to seek further information to answer their questions. Almost one in two patients $(49.8 \%)$ were relieved to get the information, while $23.2 \%$ experienced an increase in anxiety because of the knowledge acquired.
Table 3 Explanation of the written IC and further oral information $(n=560)$

\begin{tabular}{lll}
\hline & $\mathrm{n}$ & $\%$ \\
\hline Was the consent explained upon delivery? & & \\
Yes & 367 & 65.6 \\
No & 59 & 10.5 \\
Partially & 31 & 5.5 \\
No, I designated a relative & 14 & 2.5 \\
I have not signed / I don't remember & 89 & 15.9 \\
Total & 560 & 100.0
\end{tabular}

Did you receive further oral information besides the written consent?

$\begin{array}{lll}\text { Yes } & 526 & 93.9 \\ \text { No } & 20 & 3.6 \\ \text { Given to a relative } & 14 & 2.5 \\ \text { Total } & 560 & 100.0\end{array}$

Degree of completeness of the oral information ${ }^{a}$

$\begin{array}{lll}\text { Partial } & 361 & 68.6 \\ \text { Complete } & 165 & 31.4 \\ \text { Total } & 526 & 100.0\end{array}$

When was the further oral information provided? ${ }^{a}$

$\begin{array}{llll}\text { Progressively during pre-surgery examination } & 351 & 66.7\end{array}$

$\begin{array}{lll}\text { On admission } & 94 & 17.9\end{array}$

On delivery of IC form $\quad 44 \quad 8.3$

$\begin{array}{lll}\text { Before entering the operating room } & 33 & 6.3\end{array}$

$\begin{array}{lll}\text { At the first examination } & 3 & 0.6\end{array}$

The day after surgery $\quad 1 \quad 0.2$

$\begin{array}{lll}\text { Total } & 526 & 100.0\end{array}$

Was it understandable? ${ }^{\mathrm{a}}$

$\begin{array}{lll}\text { Yes } & 511 & 97.1\end{array}$

$\begin{array}{lll}\text { Partially } & 15 & 2.9\end{array}$

$\begin{array}{lll}\text { No } & 0 & 0.0\end{array}$

$\begin{array}{lll}\text { Total } & 526 & 100.0\end{array}$

among those who received information

Table 4 Type of oral information delivered by physician $(n=$ 560)

\begin{tabular}{lll}
\hline & $\mathrm{n}$ & $\%$ \\
\hline Diagnosis & 520 & 92.8 \\
Type of surgery & 494 & 88.2 \\
Prognosis & 416 & 74.2 \\
Post-operative progress & 384 & 68.6 \\
Benefits of surgery & 381 & 68.0 \\
Outcome of non treatment & 362 & 64.6 \\
Alternatives to the proposed surgery & 354 & 63.2 \\
Chances of success of the surgery & 346 & 61.8 \\
Potential complications of the surgery & 300 & 53.6 \\
\hline
\end{tabular}


Table 5 Effects of the written IC and the oral information on the patient's decision making $(n=444)$

\begin{tabular}{|c|c|c|}
\hline & $\mathrm{n}$ & $\%$ \\
\hline \multicolumn{3}{|c|}{$\begin{array}{l}\text { Written IC and oral information influenced the decision to proceed to } \\
\text { the surgery? }\end{array}$} \\
\hline A lot & 41 & 9.2 \\
\hline Somewhat & 46 & 10.4 \\
\hline A little & 48 & 10.8 \\
\hline No & 309 & 69.6 \\
\hline Total & 444 & 100.0 \\
\hline \multicolumn{3}{|c|}{ Which one mainly influenced your decision? ${ }^{a}$} \\
\hline Oral information & 90 & 66.7 \\
\hline Both & 28 & 20.7 \\
\hline I don't know & 14 & 10.4 \\
\hline Written IC form & 3 & 2.2 \\
\hline Total & 135 & 100.0 \\
\hline
\end{tabular}

Compared to the information received. What would you want to know? ${ }^{\mathrm{b}}$

$\begin{array}{lll}\text { More } & 55 & 10.5 \\ \text { No more, no less } & 464 & 88.2 \\ \text { Less } & 7 & 1.3 \\ \text { Total } & 526 & 100.0\end{array}$

Have you had the opportunity to ask any questions?

Yes, and I had exhaustive answers

$361 \quad 64.4$

Not asked questions

$183 \quad 32.7$

Yes, without satisfactory answers

$16 \quad 2.9$

Total

560

100.0

Consequences of the received information ${ }^{b}$

Relief/Improvement in symptoms $\quad 262 \quad 49.8$

Indifference $\quad 142 \quad 27.0$

Anxiety/Worsening of the symptoms $\quad 122 \quad 23.2$

$\begin{array}{lll}\text { Total } & 526 & 100.0\end{array}$

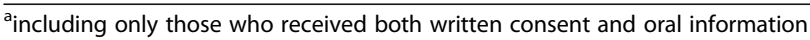
and only those whose decision had been influenced

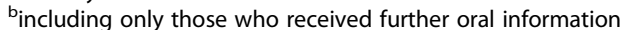

Table 6 shows outcomes for patients in this study. Notably, $95.2 \%$ of respondents had no complications following surgery. Sixty-two percent said that their post-operative progress conformed to what was explained before the surgery, but almost a third (31.5\%) reported that they did not receive information about post-operative progress. Nearly all patients (93.6\%) were given instruction on self-care after discharge and, of those, $94.2 \%$ followed the guidance. Only $3.6 \%$ of the patients did not receive instructions, and $2.8 \%$ wanted to have received more information.

Younger age $(\leq 60)$ and a higher level of education (high school or degree) were the only socio-demographic characteristics statistically associated with reading of the IC
Table 6 Health outcome and coherence between indication and outcome after discharge $(n=560)$

\begin{tabular}{lll}
\hline & $\mathrm{n}$ & $\%$ \\
\hline Outcome of the surgery & & \\
Successful & 533 & 95.2 \\
Complications & 27 & 4.8 \\
Total & 560 & 100.0
\end{tabular}

Coherence of the information received with the real post-operative progress

\begin{tabular}{lll} 
Coherent & 349 & 62.3 \\
Worse than expected & 18 & 3.2 \\
Better than expected & 17 & 3.0 \\
No information & 176 & 31.5 \\
Total & 560 & 100.0 \\
Instructions on the behaviors to keep after the discharge & \\
Received & 524 & 93.6 \\
Yes, but more Instructions needed & 16 & 2.8 \\
Not received & 20 & 3.6 \\
Total & 560 & 100.0 \\
Adherence to the post-operative care indications & \\
Yes & 511 & 91.3 \\
Partially & 16 & 2.9 \\
No & 33 & 5.8 \\
Total & 560 & 100.0 \\
\hline
\end{tabular}

form, also after stratification for age $(\leq 60$ and $>60)$ of education level with Mantel-Haenszel test (Table 7).

Patients to whom the IC form had been explained or who had received additional oral information stated that they were more satisfied compared to those who had only received the written IC, $p=0,01$ (Table 8). We have considered as "satisfied" those patients who answered "no more no less" to the question "Compared to the information received, how much would you want to know?" and "not satisfied" those patients who answered "more" to the same question. Patients who responded that they wanted to have less information (7 subjects) were excluded.

\section{Discussion}

Complete information before an invasive procedure is an ethical requirement, and it is very important to involve the patient in decision-making regarding the treatment. Well-informed patients are generally more satisfied and file fewer legal claims [17-21]. Conversely, patients who were not informed about the risks of surgery regretted the decision after the surgery [11, 22-24].

We analyzed the four elements contributing to correct utilization of written IC forms: delivery, signature, reading and comprehensibility. Delivery and signature are formal and compulsory actions that comply with Italian 
Table 7 Relationship between reading written IC with age and education level of patients and Mantel-Haenszel test (M.H)

\begin{tabular}{llll}
\hline & & Yes/Total & Reading \% \\
\hline Age & $>60$ & $50 / 155$ & 32.2 \\
& $\leq 60$ & $194 / 316$ & 61.4 \\
& Total & $244 / 471$ & 51.8 \\
OR=3.33(Cl 95\%: $2.22-5.01) p=0.000$ & & \\
Education & $<$ High School & $102 / 247$ & 41.3 \\
& $\geq$ High School & $142 / 224$ & 63.4 \\
& Total & $244 / 471$ & 51.8
\end{tabular}

$\mathrm{OR}=2.46(\mathrm{Cl}: 1.70-3.57) p=0.000$

Mantel-Haenszel test

Age $>60 \quad$ Education

$\begin{array}{lll}<\text { High School } & 30 / 112 & 26.8 \\ \geq \text { High School } & 20 / 43 & 46.5 \\ \text { Total } & 50 / 155 & 32.3\end{array}$

$\mathrm{OR}=2.37(\mathrm{Cl} 95 \%: 1.14-4.92) p=0.001$

Age $\leq 60 \quad$ Education

$\begin{array}{lll}<\text { High School } & 72 / 135 & 53.3 \\ \geq \text { High School } & 122 / 181 & 67.4 \\ \text { Total } & 194 / 316 & 61.4\end{array}$

$\mathrm{OR}=1.81(\mathrm{Cl} 95 \%: 1.14-2.86) p=0.001$

M.H. test stratified for age $\mathrm{OR}=1.94($ C.I.1.32-2.90) $p=0.001$

laws. Reading and comprehensibility are key actions that allow the patient to become aware of the risk benefit of the practical intervention. Therefore, in our study the main shortcoming of the written IC process has been that almost all patients received and signed it, but only half of them read it adequately.

Possible reasons for the findings are: first, many patients showed scarce interest in the IC document, probably preferring to rely on the surgeon's expertise or they would not be able to understand. In our study, the patients with a higher educational level and who were not older than 60 years old were more likely to read the IC form [25]. Secondly, surgeons might have shown a lack of interest in the document, sought signatures without giving adequate support and motivation to the patients and hence did not explain to them the importance of reading the document [22, 26-28]. Thirdly, almost half the patients

Table 8 Relationship between patients satisfaction (not satisfied/satisfied) and oral explanation of IC form

\begin{tabular}{lllllll}
\hline $\begin{array}{l}\text { Oral } \\
\begin{array}{l}\text { explanation of } \\
\text { ICform }\end{array}\end{array}$ & $\begin{array}{l}\text { Not satisfied } \\
\mathrm{n} / \%\end{array}$ & $\begin{array}{l}\text { Satisfied } \\
\mathrm{n} / \%\end{array}$ & Total & O.R. & C.I. 95\% & $p$ \\
\hline Not explained & $25 / 15.6$ & $135 / 84.4$ & 160 & $\mathbf{1 , 0 0}$ & & \\
Explained & $30 / 8.4$ & $329 / 91.6$ & 359 & $\mathbf{2 , 0 3}$ & $1,15-3,58$ & 0,01 \\
Total & $55 / 10.6$ & $464 / 89.4$ & 519 & & & \\
\hline
\end{tabular}

received the form immediately or just a few hours before the surgical procedure-when they were more stressed and vulnerable, with little time to read and reflect on it [13]. A probable reason for this is that in the Italian culture, physicians regard the delivery and the signing of written IC form as a fulfillment of the law [3], while more importance is given to oral information. Indeed, two-thirds of patients reported that at the handover, the consent was also explained, and almost all received information beyond what was in the IC form at various times before the surgical intervention.

In agreement with findings of other authors [29, 30], when delivering oral information, patients stated that the surgeons focus principally on the diagnosis and on the type of surgical procedure; a lower percentage of patients reported being informed about other aspects of the treatment, such as prognosis, consequences of a missed treatment or the possible surgical complications. No information was provided about possible deficiencies in the facilities' biomedical equipment or specific diagnostic tools that can reduce safety aspects of the procedures [3]. Therefore to improve the quality of communication with the written IC, we agree with Ghulam, who suggests that a structured conversation helps physicians establish relationships with the patients, facilitates the documentation and offers a valid legal proof for patients and physicians regarding the adequacy of the information provided [13].

Though there is an ethical imperative to inform the patient, it is not always reassuring to the patient: indeed, about one fourth of patients experienced nocebo effects, such as increased anxiety because of the acquired knowledge [11-14]. Moreover, the majority of patients were hardly influenced or not at all influenced by the written and oral information, having previously decided to undergo the surgery. These findings recall a well-known dilemma of IC. If IC is too detailed, it might violate the principle of nonmaleficence by causing nocebo effect. If it is less detailed, it might violate the principle of autonomy not allowing a conscious choice by the patient. Wells and Kaptchuk [14] try to overcome this dilemma by proposing a contextualized informed consent. They consider it an ethical procedure whereby a provider takes into account the possible side effects, the typology of patient, and the diagnosis involved, to provide information tailored in view to reduce expectancy-induced side effects, and, at the same time, to respect patient autonomy and conscious choice. Therefore, the previous relative definition of "complete" IC, as reported at the beginning of the discussion, should be concluded with the statement "considering the possibility of inducing nocebo effect". 
The main limitation of the present survey is the potential recall bias because the information was obtained through face-to-face interview many days after the delivery of the written IC and after discharge that caused many answers "I don't know/ I don't remember" reported in the tables. The patients satisfaction has not been collected as direct question, but has been evaluated as surrogate variable, interpreting the answer to a different question.

Furthermore, patients who had required intensive care or had been brought back into surgery were excluded. Therefore, the results would not be generalized to patients in more severe settings.

\section{Conclusion}

Written IC is essential in medicine in order to ensure that patients have the needed information to make an aware choice and consenting to treatment. Furthermore, various authors have demonstrated that written information is best understood by patients who can read the information many times and can discuss it with relatives and friends [3, 13], who are reassuring points of reference for post-operative progress. Oral information is not always easily absorbed because of the escalated stress level just prior to surgery [13].

In our experience, written information has not provided patients with adequate decision-making tools for imminent health matters, while pre-operative oral information was better suited to meet patients' needs.

Finally, we agree with authors who think it is necessary that physicians also enhance their communication skills to enable them to build alliances with patients in order to become effective partners and ensure that patients can make informed choices in accordance with their own feelings and values [3, 22, 31, 32]. Because of this, we must implement communication training for doctors as an integral part of clinical skills to reach a complete patient compliance. This must be incorporated into training at all levels, including postgraduate medical programs, in order to improve physicians' listening skills and develop interactive communication skills. Such a trained physician can help patients in defining what is the best choice to make in order to improve their own health status, in accordance to their experiences and values and within a relationship of trust and collaboration (shared decision making) [33]. This seems to be the main way to ensure patients' "self-determination" in health care.

\section{Additional files}

Additional file 1: Questionnaire: Patient's informed consent procedure. (PDF 497 kb)

Additional file 2: Consent Data base. (XLS $164 \mathrm{~kb}$ )
Abbreviation

IC: Informed Consent; M.H: Mantel-Haenszel test; OR: Odds Ratio

\section{Acknowledgements}

Viola Del Prete: Department of Experimental Medicine.

Concetta Paola Pelullo: Department of Experimental Medicine.

Mario Mensorio: General hospital "Sant' Anna and San Sebastiano" Caserta.

Vincenzo Castaldo: General Hospital "San Giuseppe Moscati" Avellino.

Federica D'Agostino: General Hospital "Gaetano Rummo" Benevento.

Andreo De Stefano: Local "Civil Hospital" Nola.

Franco Paradiso: General Hospital "Antonio Cardarelli".

Funding

No funding was received.

Availability of data and materials

The data supporting the results are reported in Additional files 1 and 2.

\section{Authors' contributions}

FA conceived the study and revised it critically for important intellectual content; EA participated in its design and coordination, in interpretation data and wrote the manuscript; SB, TDL, FMC has been involved in collection of data; they performed data entry and statistical analysis and they contributed to data interpretation; MC. has been involved in collection of data and contributed to data interpretation. All authors read and approved the final manuscript.

\section{Ethics approval and consent to participate}

Approved by Ethics Commettee of "Seconda Università degli Studi di Napoli" Prot. $1116-30$ July 2015

We obtained written informed consent from all patients.

\section{Consent for publication}

"Not applicable" because in the manuscript and in the data set there aren't individual patient data.

Competing interests

All the authors declare that they have no competing interests both financial and non-financial.

\section{Publisher's Note}

Springer Nature remains neutral with regard to jurisdictional claims in published maps and institutional affiliations.

Received: 13 February 2017 Accepted: 25 December 2018

Published online: 07 January 2019

References

1. Makoul G. Communication skills education in medical school and beyond. JAMA. 2003;289:93.

2. Cassazione Civile, sez. III, sentenza 21/07/2003 n 11316.

3. Turillazzi E, Neri M. Informed consent and Italian physicians: change course or abandon ship-from formal authorization to a culture of sharing. Med Health Care Philos. 2015;18:449-53.

4. Henderson GE. Is informed consent broken? Am J Med Sci. 2011;342:267-72.

5. Lidz CW. Informed consent: a critical part of modern medical research. Am J Med Sci. 2011;342:273-5.

6. Parvizi J, Chakravarty R, Og B, Rodriguez-Paez A. Informed consent: is it always necessary? Injury. 2008;39:651-5.

7. Paterick TJ, Carson GV, Allen MC, Paterick TE. Medical informed consent: general considerations for physicians. Mayo Clin Proc. 2008;83:313-9.

8. Schenker $Y$, Fernandez A, Sudore R, Schillinger D. Interventions to improve patient comprehension in informed consent for medical and surgical procedures: a systematic review. Med Decis Mak. 2011;31:151-73.

9. Terry PB. Informed consent in clinical medicine. Chest. 2007;131:563-8.

10. Beauchamp TL, Childress JF. Principles of biomedical ethics. 6th ed. New York: Oxford University Press; 2009.

11. Ashraf B, Saaiq M, Zaman KU. Qualitative study of nocebo phenomenon (NP) involved in doctor-patient communication. Int J Health Policy Manag. 2014;3:23-7.

12. Cohen S. The nocebo effect of informed consent. Bioethics. 2014;28:147-54. 
13. Ghulam AT, Kessler M, Bachmann LM, Haller U, Kessler TM. Patients' satisfaction with the preoperative informed consent procedure: a multicenter questionnaire survey in Switzerland. Mayo Clin Proc. 2006;81:307-12.

14. Wells RE, Kaptchuk TJ. To tell the truth, the whole truth, may do patients harm: the problem of the nocebo effect for informed consent. Am J Bioeth. 2012;12:22-9.

15. Ochieng J, Buwembo W, Munabi I, Ibingira C, Kiryowa H, Nzarubara G, Mwaka E. Informed consent in clinical practice: patients' experiences and perspectives following surgery. BMC Res Notes. 2015;8:765.

16. Ochieng J, Ibingira C, Buwembo W, Munabi I, Kiryowa H, Kitara D, Bukuluk P, Nzarubara G, Mwaka E. Informed consent practices for surgical care at university teaching hospitals: a case in a low resource setting. BMC Med Ethics. 2014;15:40.

17. Albera R, Argentero P, Bonziglia S, De Andreis M, Preti G, Palonta F, Canale A. Informed consent in ENT. Patient's judgement about a specific consensus form. Acta Otorhinolaryngol Ital. 2005;25:304-11.

18. Betti S, Sironi A, Saino G, Ricci C, Bonavina L. Effect of the informed consent process on anxiety and comprehension of patients undergoing esophageal and gastrointestinal surgery. J Gastrointest Surg. 2011;15:922-7.

19. Jahan F, Roshan R, Nanji K, Sajwani U, Warsani S, Jaffer S. Factors affecting the process of obtaining informed consent to surgery among patients and relatives in a developing country: results from Pakistan. East Mediterr Health J. 2014;20:569-77.

20. Leclercq WK, Keulers BJ, Houterman S, Veerman M, Legemaate J, Scheltinga MR. A survey of the current practice of the informed consent process in general surgery in the Netherlands. Patient Saf Surg. 2013;7:4.

21. Leclercq WK, Keulers BJ, Scheltinga MR, Spauwen PH, van der Wilt GJ. A review of surgical informed consent: past, present, and future. A quest to help patients make better decisions. World J Surg. 2010;34:1406-15.

22. Ashraf B, Tasnim N, Saaiq M, Zaman KU. An audit of the knowledge and attitudes of doctors towards surgical informed consent (SIC). Int J Health Policy Manag. 2014;3:315-21.

23. Kenton K, Pham T, Mueller E, Brubaker L. Patient preparedness: an important predictor of surgical outcome. Am J Obstet Gynecol. 2007;197:654.e1-6.

24. Kurt E, Ucar M, Atac A. Quality of an informed consent prior to a surgical intervention? Experience of a teaching hospital Pak J Med Sci. 2016;32:206-10.

25. Fink AS, Prochazka AV, Henderson WG, Bartenfeld D, Nyirenda C, Webb A, Berger DH, Itani K, Whitehill T, Edwards J, Wilson M, Karsonovich C, Parmelee P. Predictors of comprehension during surgical informed consent. J Am Coll Surg. 2010;210:919-26.

26. Brezis M, Israel S, Weinstein-Birenshtock A, Pogoda P, Sharon A, Tauber R. Quality of informed consent for invasive procedures. Int I Qual Health Care. 2008;20:352-7.

27. Falagas ME, Akrivos PD, Alexiou VG, Saridakis V, Moutos T, Peppas G, Kondilis BK. Patients' perception of quality of pre-operative informed consent in Athens, Greece: a pilot study. PLoS One. 2009;4:e8073.

28. Giudici K, Gillois P, Coudane H, Claudot F. Oral information in orthopaedics: how should the patient's understanding be assessed? Orthop Traumatol Surg Res. 2015;101:133-5.

29. Abed H, Rogers R, Helitzer D, Warner TD. Informed consent in gynecologic surgery. Am J Obstet Gynecol. 2007;197:674.e1-5.

30. McGaughey I. Informed consent and knee arthroscopies: an evaluation of patient understanding and satisfaction. Knee. 2004;11:237-42.

31. Keulers BJ, Scheltinga MR, Houterman S, Van Der Wilt GJ, Spauwen PH. Surgeons underestimate their patients' desire for preoperative information. World J Surg. 2008;32:964-70

32. Steinemann S, Furoy D, Yost F, Furumoto N, Lam G, Murayama K. Marriage of professional and technical tasks: a strategy to improve obtaining informed consent. Am J Surg. 2006;191:696-700

33. Elwyn G, Frosch D, Thomson R, Williams NJ, Lloyd A, Kinnersley P, Cording E, Tomson D, Dodd C, Rollnick S, Edwards A, Barry M. Shared decision making: a model for clinical practice. J Gen Intern Med. 2012;27(10):1361-7.

Ready to submit your research? Choose BMC and benefit from:

- fast, convenient online submission

- thorough peer review by experienced researchers in your field

- rapid publication on acceptance

- support for research data, including large and complex data types

- gold Open Access which fosters wider collaboration and increased citations

- maximum visibility for your research: over $100 \mathrm{M}$ website views per year

At BMC, research is always in progress.

Learn more biomedcentral.com/submissions 